ment (the driving force to return to the substance abused) with dopaminergic pathways in the nucleus accumbens, in the context of socio-cultural models of addiction: social deprivation promotes drug abuse.

Politics and organized crime being what they are, it will of course take a lot more than this book seriously to influence the entrenched resistance to changing drug policy. This is a shame. Addictus, Robson reminds us, was a victim of the courts in ancient Rome, which handed him over as a slave to his creditor because he could not pay off his debts. A neat metaphor for Robson's views.

Alison Abbott is Senior European Correspondent for Nature, based in Munich.

\section{Thinking on one's feet}

\section{Annette Karmiloff-Smith and \\ Mark H. Johnson}

A Dynamic Systems Approach to the Development of Cognition and Action. By Esther Thelen and Linda B. Smith. MIT Press: 1994. Pp. 376. £44.95, \$67.50.

DEVELOPMENTAL theories are going dynamic. Psychologists no longer think of nature and nurture in terms of a dichotomy. But until recently there were few alternatives to the biologically implausible dissociation of cognition into 'innate' and 'acquired' components. Two recent approaches - connectionist models of cognitive change and dynamic systems approaches to motor development - now promise to change the way many think about development.

This book attempts to set the agenda for broadening the dynamic systems approach to a wide range of phenomena in brain, cognitive and behavioural development. Thinking, according to Thelen and Smith, is like walking: the emergent property of multilevel dynamics. Irrespective of whether they succeed in their aims, this is a challenging book. The questions addressed go to the very heart of crucial developmental issues. How does experience shape the developing brain? Where do novelty and flexibility come from? How is knowledge assembled in real time? What is the role of temporal versus spatial contingencies? Do constraints on, say, language development imply a genetic blueprint for language or the emergence of constraints from a variety of different levels of interaction? Or in other words, what causes developmental change?

The dynamic systems approach holds that there is no single cause of developmental change. Although the endpoints of

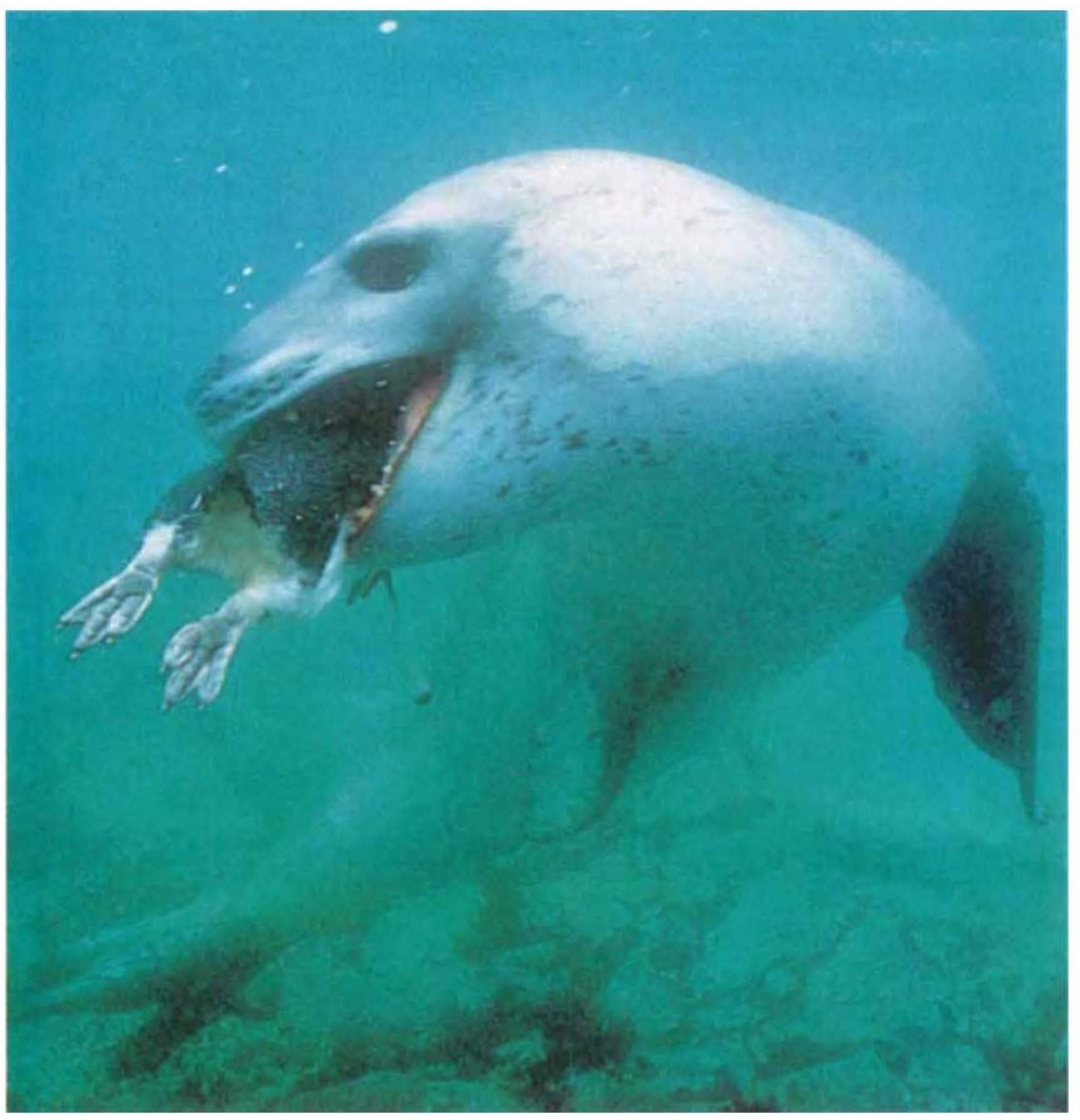

A PENCHANT for penguins - a leopard seal Hydrurga leptonyx seizes a penguin underwater. Only males appear to indulge in this seasonal eating habit. Picture taken from Seals and Sea Lions of the World by Nigel Bonner (Blandford, £18.99).

human development are complex and unique, the processes by which we reach those endpoints are considered to be the same as those that govern development in very simple organisms, and even in some complex nonliving systems. Genetic determinism, the authors argue, simply sidesteps the problem of origins, dumping it onto the laps of evolutionists. Variable, task-sensitive effects are not just noise in a grand developmental plan, but are the raw material for developmental change. The central theoretical question is not how cognition reaches stability, but rather how cognition calibrates its continual stabilization-destabilization over real time and developmental time in the face of an everchanging world.

The authors are to be congratulated on taking development seriously. Theirs is a radical departure from most of current cognitive development theory which focuses on innate specifications, symbolic representations and the attainment of stable structures. Many of the authors' arguments are reminiscent of those of Piaget. They give primacy to action, perception and movement as well as to the ability of the organism to modify and equilibrate itself. Where they differ from the Piagetian view is in arguing that mental activity is a dynamic assembly of multiple levels (neural, social, physical) rather than a hierarchy of increasingly stable mental structures. The authors' dismissal of the need to specify the nature of mental representations, however, goes beyond disagreement with Piagetian theory.

The dynamic systems approach is readily applicable to behavioural output, as the book nicely illustrates. At this level, reducing the importance of the brain to only one of many sources of control parameters with the same status as muscle strength may be plausible. When we move to cognitive development, however, the special status of representations in the brain becomes essential, in our view. Not all developmental scientists consider the term 'representation' to mean something static. The authors rightly reject the digital computer metaphor for cognitive development popular in the 1970 s and 1980 s, but in denying the importance of representations, they throw the baby out with the considerable quantity of bathwater.

Their attempt to move from cyclical behavioural output to cognition (sans representations) manifests itself in two ways. First, they cite evidence from neuroscience that information processing in the 